\title{
Thermal Hydraulic Analysis Improvement for the IEA-R1 Research Reactor and Fuel Assembly Design Modification
}

\author{
Pedro Ernesto Umbehaun, Walmir Maximo Torres, José Antonio Batista Souza, \\ Mitsuo Yamaguchi, Antonio Teixeira e Silva, Roberto Navarro de Mesquita, \\ Nikolas Lymberis Scuro, Delvonei Alves de Andrade
}

Nuclear and Energy Research Institute (Instituto de Pesquisas Energéticas e Nucleares), São Paulo, Brazil Email: umbehaun@ipen.br,wmtorres@ipen.br, jasouza@ipen.br, mitsuo@ipen.br, teixeira@ipen.br, rnavarro@ipen.br, nikolas.scuro@ipen.br, delvonei@ipen.br

How to cite this paper: Umbehaun, P.E., Torres, W.M., Souza, J.A.B., Yamaguchi, M., e Silva, A.T., de Mesquita, R.N., Scuro, N.L. and de Andrade, D.A. (2018) Thermal Hydraulic Analysis Improvement for the IEA-R1 Research Reactor and Fuel Assembly Design Modification. World Journal of Nuclear Science and Technology, 8, 54-69. https://doi.org/10.4236/wjnst.2018.82006

Received: February 11, 2018

Accepted: April 6, 2018

Published: April 9, 2018

Copyright (c) 2018 by authors and Scientific Research Publishing Inc. This work is licensed under the Creative Commons Attribution International License (CC BY 4.0).

http://creativecommons.org/licenses/by/4.0/

\begin{abstract}
This paper presents the sequence of activities to improve the thermal hydraulic analysis of the IEA-R1 research reactor to operate in safe conditions after power upgrade from 2 to $5 \mathrm{MW}$ and core size reduction from 30 to 24 fuel assemblies. A realistic analysis needs the knowledge of the actual operation conditions (heat flow, flow rates) beyond the geometric data and the uncertainties associated with manufacturing and measures. A dummy fuel assembly was designed and constructed to measure the actual flow rate through the core fuel assemblies and its pressure drop. First results showed that the flow distribution over the core is nearly uniform. Nevertheless, the values are below than the calculated ones and the core bypass flow rate is greater than those estimated previously. Based on this, several activities were performed to identify and reduce the bypass flow, such as reduction of the flow rate through the sample irradiators, closing some unnecessary secondary holes on the matrix plate, improvement in the primary flow rate system and better fit of the core components on the matrix plate. A sub-aquatic visual system was used as an important tool to detect some bypass flow path. After these modifications, the fuel assemblies flow rate increased about $13 \%$. Additional tests using the dummy fuel assembly were carried out to measure the internal flow distribution among the rectangular channels. The results showed that the flow rate through the outer channels is $10 \%-15 \%$ lower than the internal ones. The flow rate in the channel formed between two adjacent fuel assemblies is an estimated parameter and it is difficult to measure because this is an open channel. A new thermal hydraulic analysis of the outermost plates of the fuel assemblies takes into account all this information. Then, a fuel design modifica-
\end{abstract}


tion was proposed with the reduction of $50 \%$ in the uranium quantity in the outermost fuel plates. In order to avoid the oxidation of the outermost plates by high temperature, low flow rate, a reduction of $50 \%$ in the uranium density in the same ones was shown to be adequate to solve the problem.

\section{Keywords}

Nuclear Research Reactor, Uranium Reduction, Thermal Hydraulic Analysis, Flow Measurement, Dummy Fuel Assembly

\section{Introduction}

The IEA-R1 research reactor is a $5 \mathrm{MW}$ pool type, light water cooled and moderated, classified among the Material Testing Reactor (MTR) type. IEA-R1 can be considered a multipurpose reactor. It has been used for basic and applied research in Nuclear Physics, training and also for radioisotopes production.

In 1995, IPEN decided to modernize and upgrade the power from 2 to $5 \mathrm{MW}$ and increase its operational cycle from $8 \mathrm{hrs}$ a day, 5 days a week to $120 \mathrm{hrs}$ continuous per week. In order to optimize the neutron flux and to have enough reactivity for continuous operation, the active core was reduced from 30 to 24 fuel assemblies.

To accomplish safety requirements, a set of actions were taken following the recommendations of the IAEA [1] applied to research reactors. Such actions were the modernization of some existing systems, design of new ones, safety evaluation and licensing.

A loss of coolant accident analysis, LOCA, by [2] pointed the need for an emergency core coolant system, ECCS, [3]. Besides, motorized valves were installed in the pool inlet and outlet to prevent LOCA. Air conditioning and ventilation system, ACVS, were resized and modernized to work within the $5 \mathrm{MW}$ operational conditions. Thermal hydraulic analysis, considering new operational conditions, was also necessary. Heat flux distribution, geometric characteristics, properties of the materials and flow rate through the fuel assemblies were considered as well as all the associated uncertainties. The flow rate among the fuel assemblies is difficult to know with precision due to the complex geometry of the core, which has several components. On the other hand, there is no cross flow and turbulent mixing inside the MTR fuel assemblies, so that the thermal hydraulic analysis of the reactor core becomes very simple, so as to consider a single flow channel, usually the hot channel under more severe conditions.

\section{Thermal Hydraulic Analysis}

Flow rates at the fuel assemblies must be verified if these parameters obey the fuel plates design limits. The core thermal hydraulic design of the IEA-R1 was based on correlations accepted by the IAEA, as set in the documents [4] and [1]. The following limits were imposed to its design: 
a) The coolant temperature shall be kept below the saturation;

b) The clad temperature shall be kept bellow $95^{\circ} \mathrm{C}$ [5] to avoid corrosion;

c) The peak clad surface temperature shall be kept $30 \%$ below the Onset of Nucleate Boiling, ONB, temperature [5];

d) The coolant velocity shall be limited to $2 / 3$ of the critical velocity;

e) The peak heat flux shall be kept bellow the heat flux to avoid flow instability rate, FIR; and

f) The peak heat flux shall be kept bellow the Critical Heat Flux, CHF.

The goal is to verify if these parameters are in accordance with the design limits. The design limits are derived from safety criteria, imposed to assure that, during any operational condition, proper core cooling is provided to keep the integrity of the reactor fuel assembly.

\subsection{Thermal Hydraulic Model}

A model MTRCR-IEA-R1 based on the commercial code Engineering Equation Solver-EES [6], was developed [7] to perform thermal hydraulic analysis of fuel assembly. It permits a steady-state thermal hydraulics analysis performed by computer codes like COBRA-3C/RERTR [8] and PARET [9] and also to analyse fuel assembly parallel channels with different cooling flow rate and/or different geometry. The developed methodology is used for the calculation of the cooling flow distribution and the thermal hydraulics analysis of the IEA-R1 reactor core.

The calculations are performed using the conduction and convection heat transfer equations for the rectangular channels formed by the fuel plates with coolant flowing down, as shown in Figure 1. The following heat changes were considered in the model: a) transversal heat conduction in the fuel plates; b) convection from cladding surface to the fluid flow and c) enthalpic transport due to fluid flow. Axial conduction in the fuel plates and coolant were not considered in the calculations due to geometric characteristics.

The uncertainties on variables, which determine the operating temperatures and the critical phenomena margins, are also evaluated. The uncertainties considered can be grouped into four different categories:

a) Fabrication tolerances in the geometric features of the Fuel Assembly;

b) Fabrication tolerances in the Uranium distribution in the Fuel Assembly;

c) Systematic uncertainties in the correlations used; and

d) Uncertainties in operating conditions (power level, coolant flow rate, inlet temperatures).

The equations used to evaluate the deviation in safety-related variables combine statistical and systematic error propagation. The way in which the errors are treated and propagated is fully described in [7].

Additional detailed information about the methodology used in the thermal hydraulic analyses is presented in [7]. The resulting equation system formed by the conservation equations was solved, for steady state condition, using Engineering Equation Solver software, EES, developed by [6]. The geometry and ma- 
terial properties (Table 1), as well as its uncertainties (Table 2) necessary for the analysis, are supplied by the fuel assembly design database. The flow rates in the internal channels were considered constant and uniformly distributed among them.
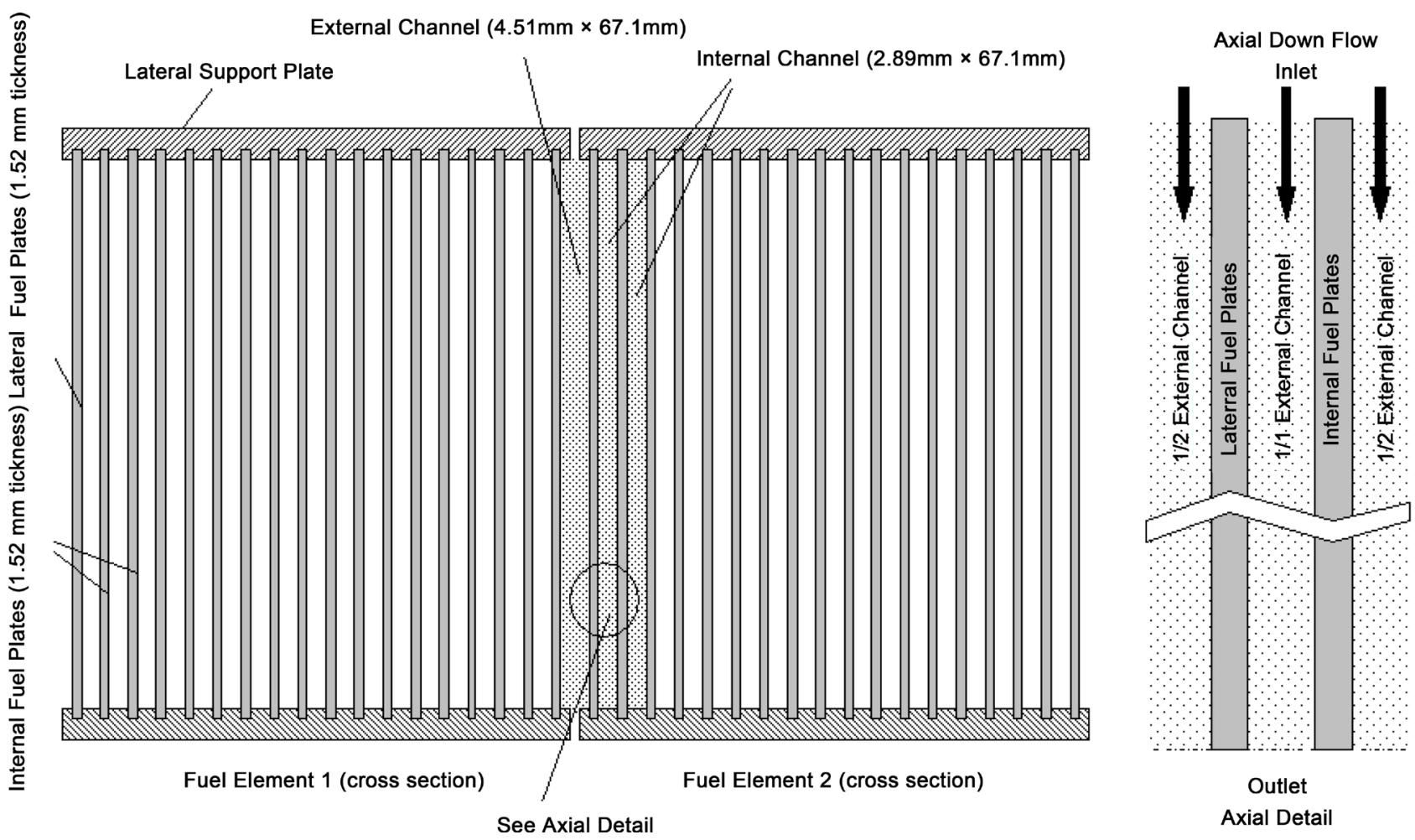

Figure 1. Thermal model sketch (two fuel element).

Table 1. Main design parameters of IEA-R1 research reactor.

\begin{tabular}{ccl}
\hline Reactor parameter & Data & Notes \\
\hline Max. inlet temperature & $40^{\circ} \mathrm{C}$ & None \\
Number of fuel plates in Standard fuel assembly & 18 & None \\
Number of Control fuel assembly & 12 & None \\
Thickness of the fuel plate & $1.52 \mathrm{~mm}$ & None \\
Thickness of the meat & $0.76 \mathrm{~mm}$ & None \\
Thickness of the clad & $0.38 \mathrm{~mm}$ & None \\
Fuel plate dimensions & $1.52 \times 70.1 \times 625$ & \\
Fuel meat dimensions & $0.76 \times 62.6 \times 600$ & Thickness $\times$ width \\
Water channel dimensions & $2.89 \times 67.1 \times 625$ & height (mm) \\
Flow area of Internal channel & $193.9 \mathrm{~mm}^{2}$ & None \\
Flow area of External channel & $302.6 \mathrm{~mm}^{2}$ & None \\
Maximum Clad temperature & $95^{\circ} \mathrm{C}$ & None \\
Flow Instability Rate (FIR) & 2.0 & None \\
Minimum departure from nucleate boiling ratio (MDNBR) & 2.0 & None \\
\hline
\end{tabular}


Table 2. Uncertainties considered in the thermal hydraulic analysis.

\begin{tabular}{cc}
\hline Parameter & Uncertainties \\
\hline Deviation in fuel loading per plate & $12 \%$ \\
Deviation in ${ }^{235} \mathrm{U}$ density & $2 \%$ \\
Error in meat thickness & $10 \%$ \\
Power measurement & $5 \%$ \\
Power density variation & $10 \%$ \\
Flow measurement & $3 \%$ \\
Neutronic model & $10 \%$ \\
\hline
\end{tabular}

\subsection{Neutronic Calculations}

The neutronic analysis methodology is based on LEOPARD [10] [11] and HAMMER-TECHNION [12] and LEOPARD [10] codes for cross-section generation, 2DB code [13] for the core and burn-up calculations in a 2-D geometry and CITATION [14] code for a 3-D analysis. The fuel cross-section is performed with LEOPARD (version modified by University of Michigan, where a plate geometry option was included) using a standard cell model (fuel, cladding and moderator) with an extra region to take into account other regions of the fuel assembly. The HAMMER-TECHNION is used to generate the cross-sections for the non-fuel regions, such as the reflector and control rods. The reactor power history is simulated with $2 \mathrm{DB}$ in a $2-\mathrm{D}$ model. Three-dimensional calculations are finally performed with CITATION [14] for effective multiplication factor, neutron flux and power density or heat fluxes distributions, integral and differential control rod worth, reactivity coefficients and kinetic parameters.

The worst conditions are used in the thermal hydraulic calculations. Figure 2 shows the axial hot channel conditions resulting of the calculations for $5 \mathrm{MW}$ reactor operation power. The axial power peaking factor is 2.73 , corresponding to a local heat flux of q" $=63.53 \mathrm{~W} / \mathrm{cm}^{2}$.

\section{Fuel Assembly Flow Rate}

The flow rate calculated according to the IAEA TECDOC-233 [4] is given by the total flow rate of the primary system divided by the number of fuel assemblies. Bypass flow rate is not considered and, for IEA-R1, this is not a good approach as it will be shown ahead.

When flow rate measurements in the fuel assemblies are not available, they are estimated based on pressure drop correlations, flow area ratios and some experimental data for regions or components of the core. There are several components and flow paths in the core deviating flow from the active core, such as sample irradiators; secondary holes in the matrix plate and coupling valve.

A computer code named FLOW was developed to calculate the cooling flow distribution in the fuel assemblies, control assemblies, irradiators, and through the channels formed between fuel assemblies and between irradiators and 


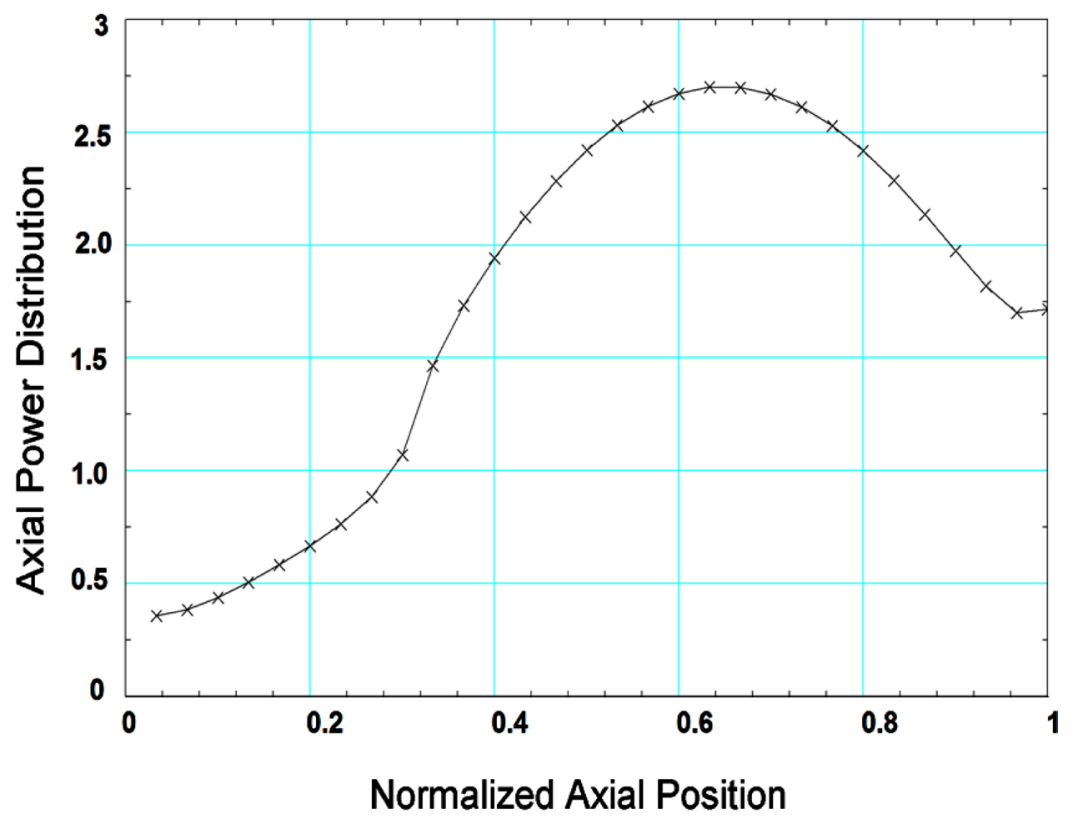

Figure 2. Axial heat flux profile of the core in hot channel.

reflectors. It is based on experimental and theoretical pressure drop correlations for these components and flow paths, and thus depends on the core configuration, i.e., number of fuel elements, irradiators with or without samples; secondary holes opened or closed in the matrix plate and channels formed between two fuel elements.

The equations used in FLOW assume that all the components form parallel closed channels and present the same pressure drop. The sum of these individual flow rates is equal to the total primary flow rate.

A computer code FLOW was validated against experimental data for the IEA-R1 research reactor core, [15] [16]. The thermal hydraulic analysis considering the flow rate calculated by FLOW indicated that the operational limits were within the safety margins. However, unusual corrosion was observed through a visual inspection system on the external plate surface for a specific fuel assembly. A detailed investigation process of this fuel assembly pointed out to an insufficient flow rate as the probable cause of corrosion. In face of this problem, it was decided to design and construct an instrumented dummy fuel assembly, named DMPV-01 [17], to measure core flow distribution and pressure drop to perform a, let's say, "more realistic" thermal hydraulic analysis.

\subsection{DMPV-01 Flow rate Distribution among Channels}

DMPV-01 also was used in the experimental circuit to measure the flow rate distribution among its internal flow channels. Two probes were constructed with $2.5 \mathrm{~mm}$ diameter in stainless steel with two pressure taps $475 \mathrm{~mm}$ distant [17] [18]. They were assembled inside the flow channels of DMPV-01 in the central region of the rectangular channels to measure the pressure drop, made by differential pressure transducer. These probes are sufficiently small to avoid signifi- 
cant changes in the channels flow distribution.

The experiments were performed for three mass flow rates through DMPV-01: 6.1, 5.2 and $4.0 \mathrm{~kg} / \mathrm{s}$ [18] [19]. The flow velocity and mass flow rate for each channel were calculated using pressure drop correlations. Figure 3 [18] shows the results of the flow rate distribution in the internal channels.

It is important to observe that the flow rate in the peripheral channels varies from $10 \%$ to $15 \%$ of the average value, depending on the flow rate through the fuel assembly. The inlet and outlet effects cause it. This information is important for the thermal hydraulic analysis of the external fuel plates.

\subsection{DMPV-01 Flow Rate Distribution among Fuel Assemblies}

According to IAEA TECDOC-233, which does not consider bypass flow, the

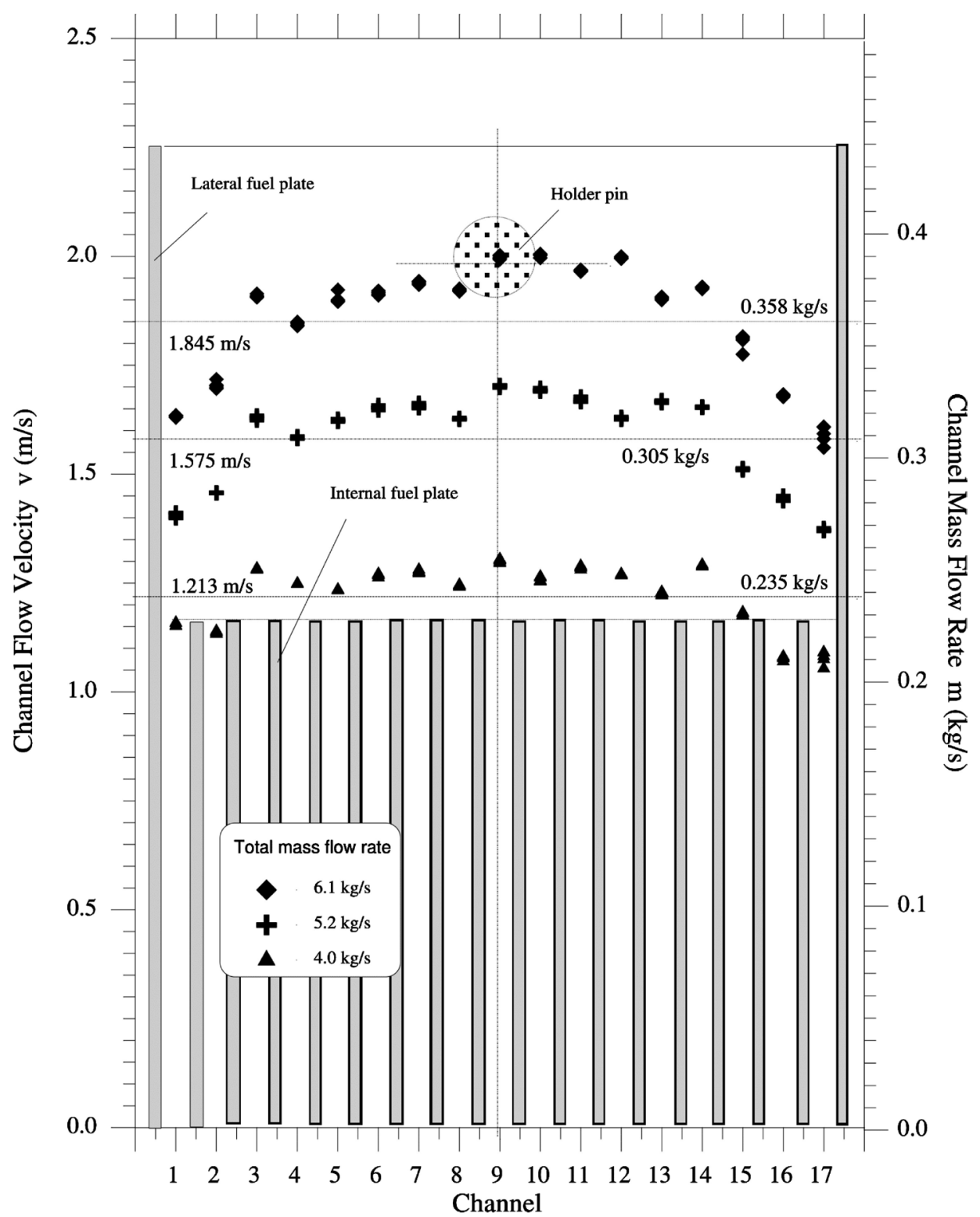

Figure 3. Channels flow distribution. 
flow rate through the fuel assemblies would be $7.85 \mathrm{~kg} / \mathrm{s}$, while calculations by FLOW resulted in $5.50 \mathrm{~kg} / \mathrm{s}$, therefore, $70 \%$ of the proposal methodology presented in TECDOC-233.

DMPV-01 was used to measure the flow rate in four different and representative positions of the core: FE153 and FE169, peripheral positions and positions FE170 and FE152, central positions [17]. These first results showed that the flow rate distribution is almost uniform with a difference of 3\% between minimum and maximum values. However, the measured flow rate was $4.84 \mathrm{~kg} / \mathrm{s}$ (average), indicating a bypass flow still higher than the expected. In this case, the value is $61.7 \%$ of the TECDOC-233 calculation, Figure 4.

Investigations were carried out by [20] to search the causes of high bypass flow rate. A sub-aquatic visual system composed by a radiation resistant video camera and display was used. Some issues were detected; a) some core components were not well fitted in the matrix plate; b) a small misalignment between the coupling device and the inferior flange of the matrix plate was also observed; c) some secondary holes in undesired positions of the matrix plate were open; and d) a high bypass flow rate through an irradiation device. Corrective actions were taken with satisfactory results. It was observed an improvement of $13 \%$ in the flow rate through the fuel assemblies, Figure 4 . The new measured values are approximately those calculated by FLOW.

\section{Thermal Hydraulic Results}

Figure 5 shows a sketch of three fuel plates (outermost and two internal fuel plate), the indication of the flow rate between two fuel assemblies (external flow) and internal flow. Temperatures $\mathrm{T} 2, \mathrm{~T} 6$ and $\mathrm{T} 8$ are the external surface temperature of external outermost plate, internal surface of the outermost plate and surface of the internal plate, respectively. $\mathrm{Tf}_{\text {ext }}$ and $\mathrm{Tf}_{\text {int }}$ are the fluid temperature of external channel on external channel, respectively.

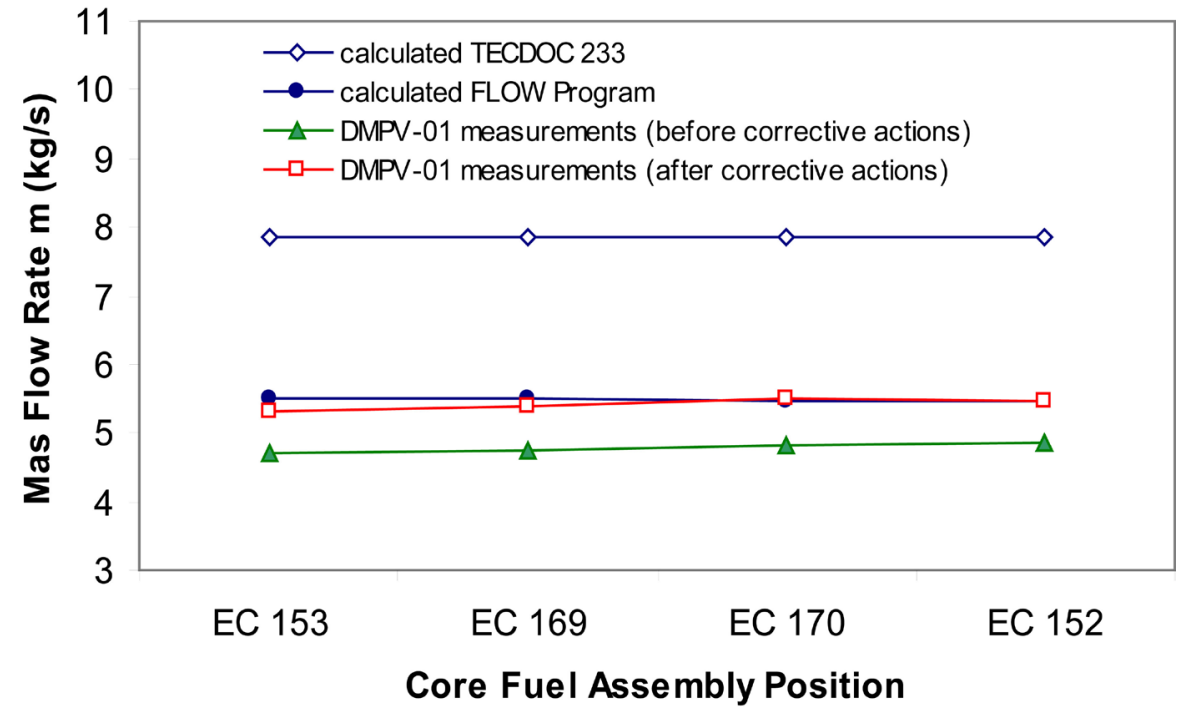

Figure 4. Measured mass flow rate in the fuel assemblies. 
Figure 6 and Figure 7 show the results of the thermal hydraulic analyses, performed for the hottest channel, in a parametric study to verify the influence of the flow rate in the safety margins of the IEA-R1 research reactor for $5 \mathrm{MW}$ operation power. The flow velocity in the external channel is assumed the same as the internal channel in order to maintain the same cooling conditions. These analyses show the results for the outermost plate and the first inner plate of the fuel assembly.

Figure 6 shows the maximum surface temperature, of outermost fuel plate

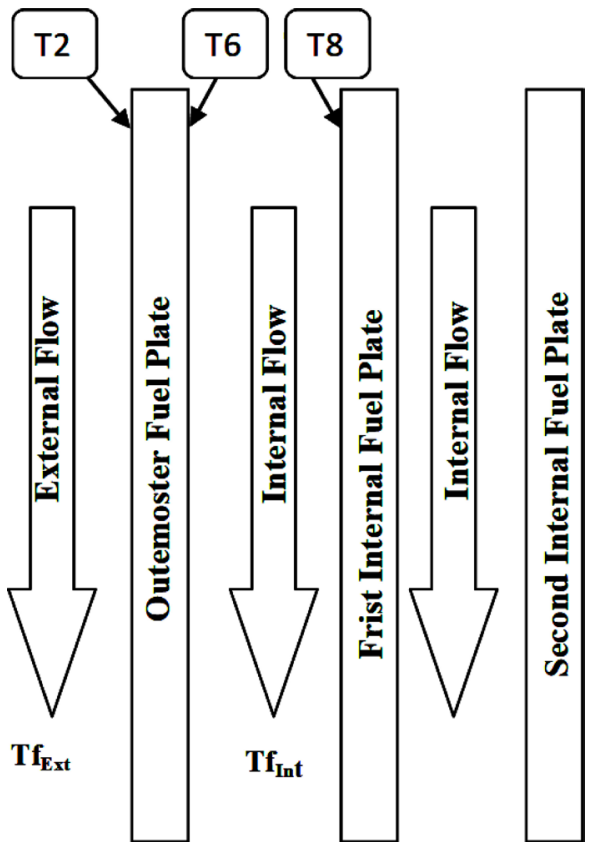

Figure 5. Sketch two fuel plates and indication of flow rate.

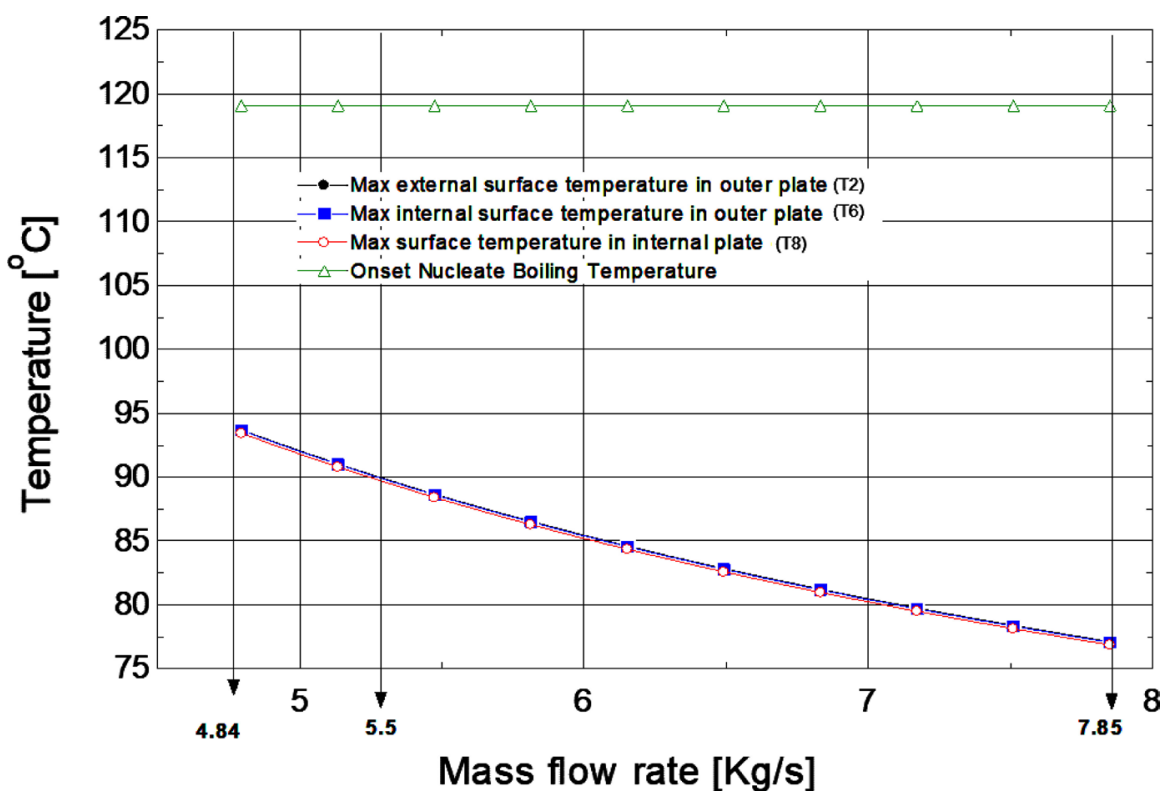

Figure 6. Maximum surface temperature along the hot channel for different flow rate conditions. 
(T2 and T6) and first internal fuel plate (T8), and the correspondent local ONB temperature. It can be noticed that the surface temperature is nearer to ONB temperature for the measured flow rate $4.84 \mathrm{~kg} / \mathrm{s}(\mathrm{v}=1.47 \mathrm{~m} / \mathrm{s})$, margin of $25.5^{\circ} \mathrm{C}$, without corrective actions, while for [4] flow condition, $7.85 \mathrm{~kg} / \mathrm{s}(\mathrm{v}=$ $2.4 \mathrm{~m} / \mathrm{s}$ ), is far from the ONB temperature, margin of $42.0^{\circ} \mathrm{C}$. The results using the flow rate calculated by FLOW and measured values after corrective actions, $5.5 \mathrm{~kg} / \mathrm{s}(\mathrm{v}=1.78 \mathrm{~m} / \mathrm{s})$, produced intermediate values, margin of $30.4^{\circ} \mathrm{C}$. Thus, flow conditions suggested by [4] in the calculations can lead to bad results, i.e., higher than safety margins.

Table 3 shows the safety margins for FIR and MDNBR for the three flow rate analyzed.

Figure 7 shows the results of the thermal hydraulic analyses assuming an average flow rate in the fuel assembly, i.e., uniformly distributed among the channels of the fuel assembly. However, the experiments with DMPV-01 demonstrated that the flow rate in the peripheral channels varies from $10 \%$ to $15 \%$ less than the average value, depending on the flow rate through the fuel assembly.

Table 3. Safety margins for FIR and MDNBR for the three flow rate analysed.

\begin{tabular}{cccc}
\hline Flow rate $(\mathrm{kg} / \mathrm{s})$ & FIR & DNBR & Condition \\
\hline 4.84 & 6.7 & 6.1 & Before correction \\
5.50 & 7.6 & 6.6 & After correction \\
7.85 & 10.9 & 8.4 & According to TECDOC-233 \\
Flow rate $(\mathrm{kg} / \mathrm{s})$ & FIR & DNBR & Condition \\
4.84 & 6.7 & 6.1 & Before correction \\
5.50 & 7.6 & 6.6 & After correction \\
\hline
\end{tabular}

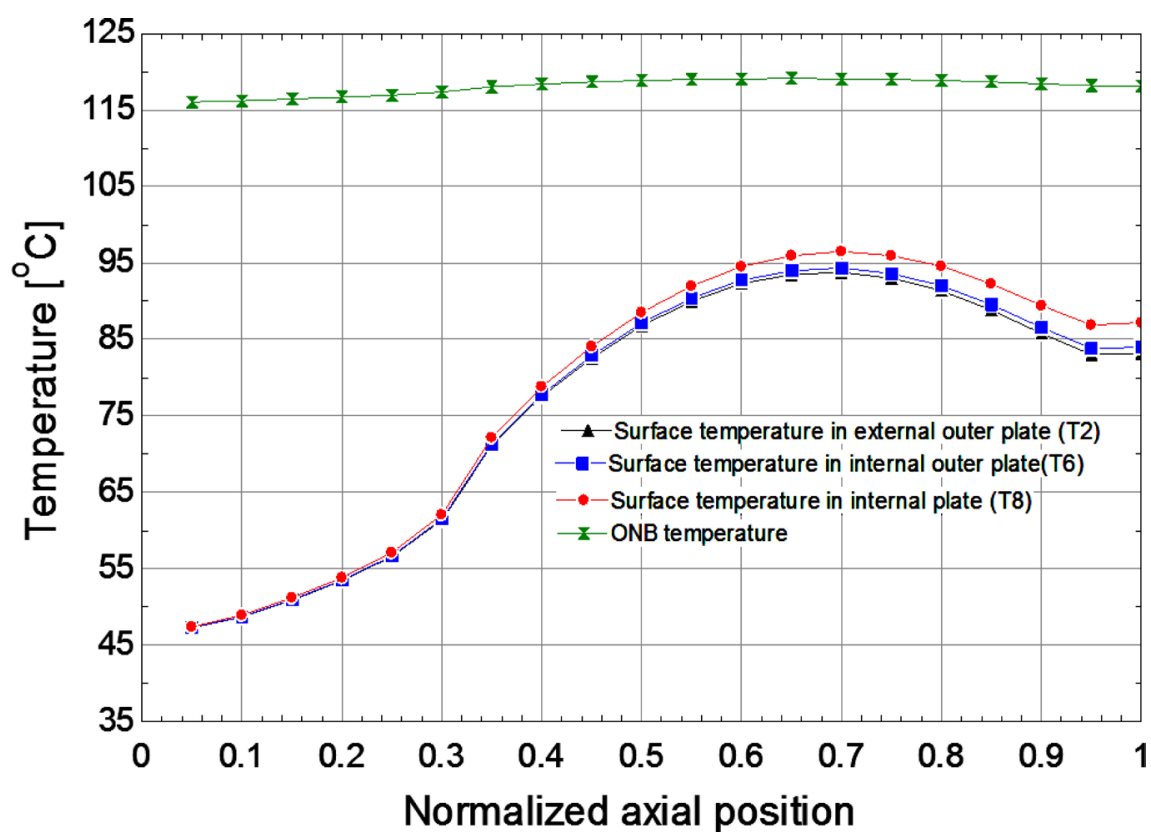

Figure 7. Surface temperature and ONB temperature along the channel. 
Figure 7 shows the results of the thermal hydraulic analyses assuming a flow rate in the two lateral channels $12.5 \%$ less than the average value $(\mathrm{v}=1.29 \mathrm{~m} / \mathrm{s})$ and the flow rate in the outer channel, between fuel assemblies, was kept the same condition ( $\mathrm{v}=1.29 \mathrm{~m} / \mathrm{s})$ of last analyses.

The surface temperature of the inner plate (T8) achieves the value of $96.5^{\circ} \mathrm{C}$, exceeding the limit of $95^{\circ} \mathrm{C}$, and the margin to $\mathrm{ONB}$ reduces to $22.6^{\circ} \mathrm{C}$.

The margins for DNBR and the rate for FI (flow instability) are 6.3 and 7.1, respectively.

An important point to emphasize in the thermal hydraulic is the cooling of the outermost fuel plates. These fuel plates are cooled by internal and external flow rates. The external flow rate through the open channel formed by two adjacent fuel assemblies is a parameter that is difficult to know with precision. The flow rate is not constant along the channel due to the characteristics of open channels, making the calculation of the temperatures of the outermost fuel plates a difficult process.

The concern with the cooling of the outermost fuel plates of the fuel assemblies is observed in other reactors, such as 1-RECH, Chile [21] and the FRG-1, Germany [22].

The fuel assemblies of research reactor RECH-1 have 16 fuel plates and fuel density is $1.7 \mathrm{gU} / \mathrm{cm}^{3}$ for the two outermost plates and $3.4 \mathrm{gU} / \mathrm{cm}^{3}$ for the $14 \mathrm{in}$ ternal fuel plates [21]. Although, the reason for this uranium density reduction on the outermost plate is not clearly addressed on the available literature, it is inferred that the objective is the temperature reduction in the plates.

A reduction in the FRG-1 core size by a factor more than two was done to increase the thermal neutron flux at the beam tubes by approximately $70 \%$. For this purpose, the ${ }^{235} \mathrm{U}$ density was increased from $3.7 \mathrm{gU} / \mathrm{cm}^{3}$ to $4.8 \mathrm{gU} / \mathrm{cm}^{3}$. Thus, the reactor size was reduced from 48 to 12 fuel assemblies and a new grid plate with shroud around the core and the support for the reactor core were designed.

Although, the reason for the installation of a shroud around the core is not clearly addressed, it is inferred that this occurred in order to increase the flow rate in the external channels to reduce or even eliminate the cross flow, thus improving the cooling of outermost plates.

Table 4 shows the results of neutronic study performed with the codes HAMMER [12] and CITATION [14] to determine the power reduction in the outermost plates with reduced uranium density.

Table 4. Uranium density $\times$ Power in outermost plate.

\begin{tabular}{cc}
\hline Uranium Density in outermost Plate & Power \\
\hline $50 \%$ & $57 \%$ \\
$60 \%$ & $66 \%$ \\
$70 \%$ & $75 \%$ \\
$100 \%$ & $100 \%$ \\
\hline
\end{tabular}


With results of Table 4 new analysis were performed maintaining the internal flow velocity in $1.57 \mathrm{~m} / \mathrm{s}$ ( $12.5 \%$ lower than the average velocity) with the same parameterization of the flow in the external channel as a function of the power in the outermost plate.

Figure 8 shows the maximum surface temperature of outermost plate (T2 and T6), internal plate (T8) and the correspondent local ONB temperature versus flow velocity in external channel (between two fuel assemblies) for $100 \%$ and $70 \%$ density of uranium in the external plate.

For outermost plates with $100 \%$ density of the inner plates a minimum flow velocity in the outer channel must be greater than $1.3 \mathrm{~m} / \mathrm{s}(\sim 0.39 \mathrm{~kg} / \mathrm{s})$ to keep the maximum surface temperature of the outermost plate (T2) below the limit $95^{\circ} \mathrm{C}$.

For outermost plates with $70 \%$ density of the inner plates a minimum flow velocity in the outer channel must be greater than $0.59 \mathrm{~m} / \mathrm{s}(\sim 0.175 \mathrm{~kg} / \mathrm{s})$ to keep the maximum surface temperature of the outermost plate (T2) below the limit $95^{\circ} \mathrm{C}$. In both cases, the margin to ONB is the same and equal to $24.1^{\circ} \mathrm{C}$.

Figure 9 shows the maximum surface temperature of outermost plate (T2 and T6), internal plate (T8) and the correspondent local ONB temperature versus flow velocity in external channel (between two fuel assemblies) for $60 \%$ and $50 \%$ density of uranium in the external plate.

For outermost plates with $60 \%$ density of the inner plates a minimum flow velocity in the outer channel must be greater than $0.39 \mathrm{~m} / \mathrm{s}(\sim 0.11 \mathrm{~kg} / \mathrm{s})$ to keep the maximum surface temperature of the outermost plate (T2) below the limit $95^{\circ} \mathrm{C}$.

For outermost plates with $50 \%$ density of the inner plates a minimum flow velocity in the outer channel must be greater than $0.22 \mathrm{~m} / \mathrm{s}(\sim 0.064 \mathrm{~kg} / \mathrm{s})$ to keep

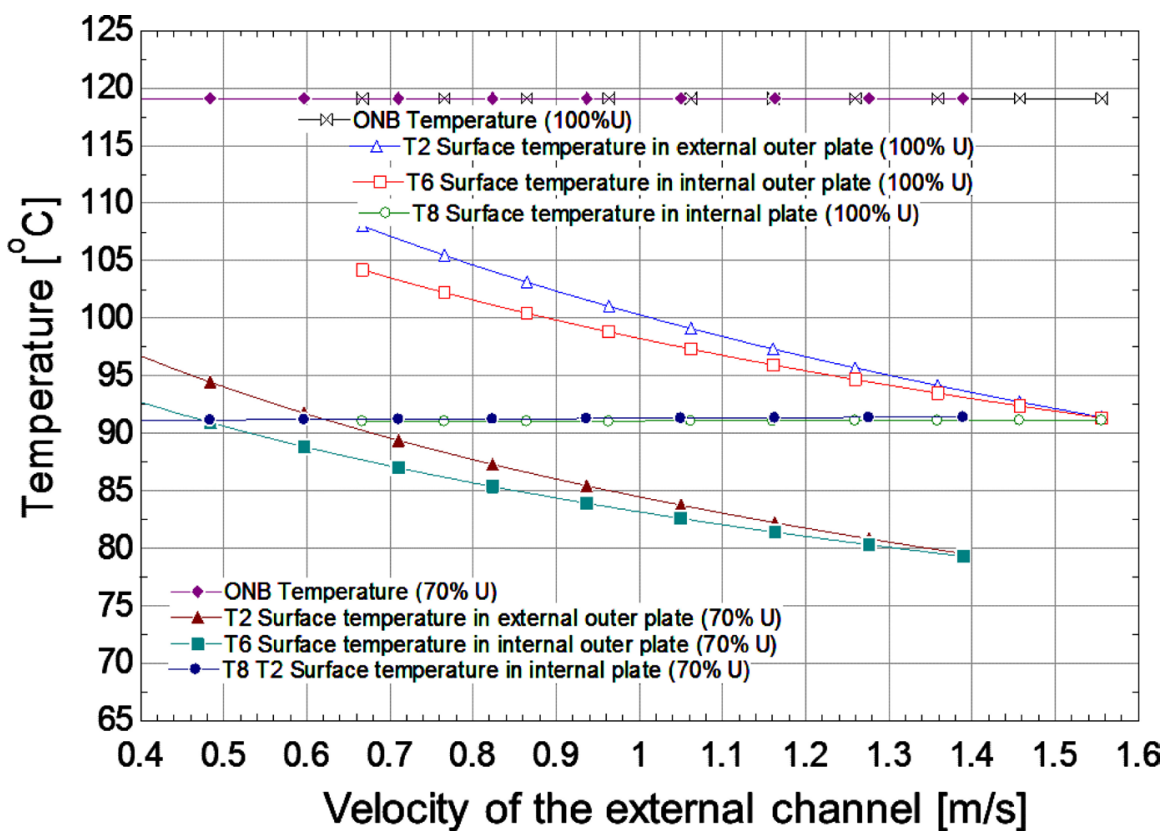

Figure 8. Maximum surface temperature versus Flow velocity in external channel. 


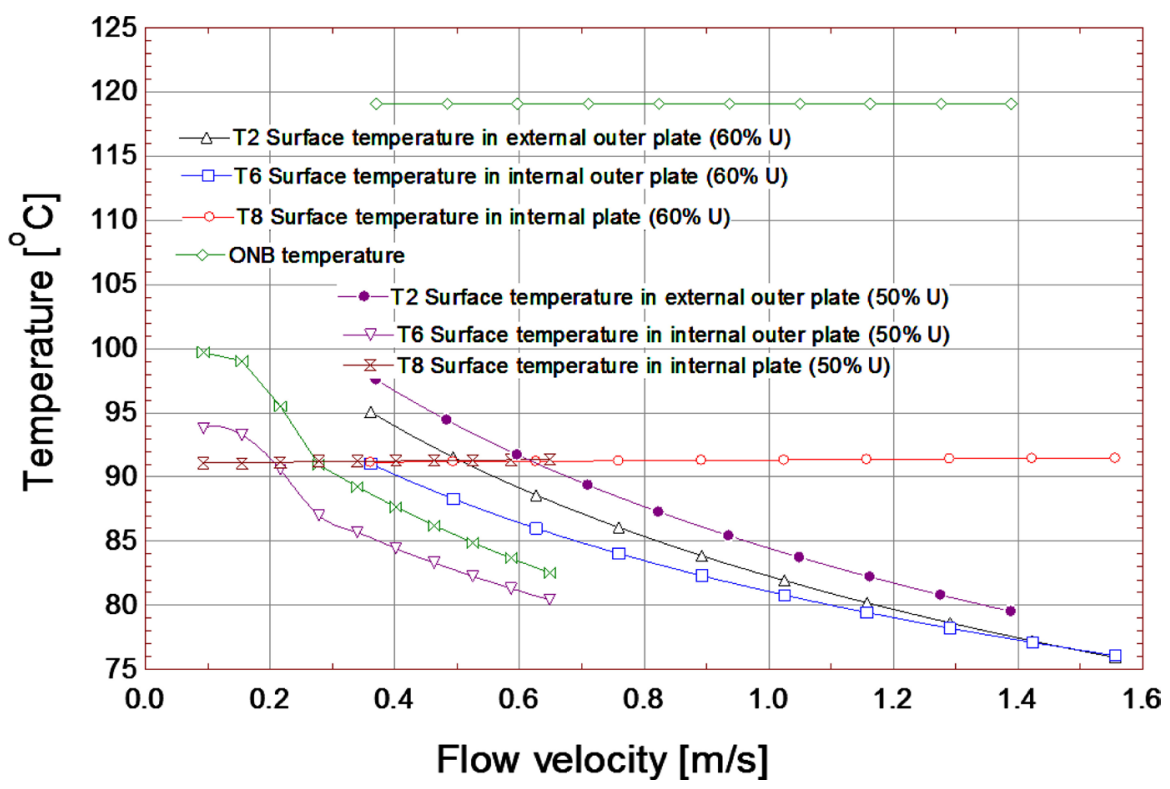

Figure 9. Maximum surface temperature versus Flow velocity in outmoster lateral plate and first internal plate.

the maximum surface temperature of the outermost plate (T2) below the limit $95^{\circ} \mathrm{C}$.

A reduction of $50 \%$ in the density of uranium in the outermost plates causes a small reduction in the burnout and in the reactivity of the core, less than $2 \%$ and $3 \%$, respectively. Nevertheless, it is a good solution to improve cooling, once for the outermost plates, the flow rate of the internal channel practically guarantees the cooling.

\section{Conclusions}

Different codes were developed in recent decades to perform thermal hydraulic analysis of research reactors, such as PARET [9], COBRA [8], RELAP5/MOD 3.3 [23] [24], CATHARE V25 1 [25] and others. Each one has different solution method, input and output data, user interfaces, precision in calculation; however, for all of them, it is very important to establish the actual research reactor operational conditions.

The thermal hydraulic analyses presented in this paper showed that all the safety margins calculated using the actual flow rate conditions are lower than those estimated with the conditions presented in [4]. It is good to remind that these safety margins are still high for the minimum flow rate. Based on this, one can conclude: a) depending on the research reactor analysed, the flow rate calculation suggested by [4] is not a good approach for high reactor power operation and for cores with complex geometries; $b$ ) it is very important to have a tool such as, the DMPV-01 dummy instrumented assembly, to allow flow rate measurements through the fuel assemblies because the core bypass flow can be higher than the expected and the pressure drop correlations could not be suitable to use in this specific case; c) sub-aquatic inspection systems are also important to 
perform core inspections. These inspections showed some graphite reflectors and irradiators not well fitted in the matrix plate and an irradiator had to be modified to reduce the bypass flow; and d) all new irradiators must be designed and experimentally tested to evaluate the core flow impact before assembling in the reactor core; e) in order to avoid the oxidation of the outermost plates by high temperature, low flow rate, a reduction of $50 \%$ in the uranium density in the same ones was shown to be adequate to solve the problem.

The measurements with the DMPV-01 showed to be very important giving us a good experience. Based on it, the reactor operators were recommended: a) reinforcing the special care to be taken with the primary system flow meter, and maintaining all its instruments calibrated. This system is very important, since it is also used to measure the reactor power operation by thermal balance; b) all the sample irradiators or any device to be assembled in the core, must be designed in order to deviate a minimum flow rate from active core for safety reasons; c) any unnecessary bypass flow paths must be identified and closed, when possible; d) it is important and recommended to have a visual inspection system for periodical inspections and to search irregularities in the reactor core and fuel assemblies.

Finally, it should be pointed out that an instrumented dummy fuel assembly, like DMPV-01, is a powerful tool to know the fuel assembly flow rate for more realistic thermal hydraulic analysis.

\section{Acknowledgements}

This research did not receive any specific grant from funding agencies in the public, commercial, or not-for-profit sectors, however the authors would like to thank the Nuclear and Energy Research Institute (IPEN-CNEN/SP) for providing all funds and laboratories necessary to the development of this research.

\section{References}

[1] International Atomic Energy Agency. (1992) Code on the Safety of Nuclear Research Reactors: Design. IAEA 45p, Safety Series 35-S1, Vienna.

[2] Maprelian, E. (1997) Programas LOSS e TEMPLOCA para Análise de Acidentes de Perda de Refrigerante no IEA-R1. Relatório Técnico IPEN no. PSI.RAS.IPEN.004, São Paulo.

[3] Torres, W.M., Baptista Filho, B.D., Ting, D.K.S. and Travessa, R. (1998) Development of an Emergency Core Cooling System for the Converted IEA-R1m Research Reactor. 21 st International Meeting on RERTR, São Paulo, Brazil.

[4] TEC-DOC 233 (1980) Research Reactor Core Conversion from Use of High Enriched Uranium to Use Low Enriched Uranium Fuels Handbook. International Atomic Energy Agency, Vienna.

[5] CNEN-IPEN (1995) Safety Analysis Report.

[6] Klein S.A. and Alvarado, F.L. (1996) EES-Engineering Equation Solver for Microsoft Windows Operating System-Version 4.334. F-Chart Software, Middleton.

[7] Umbehaun, P.E. (2000) Metodogia para análise termo-hidráulica de reatores de pesquisa tipo piscina com combustível tipo placa. M. Sc. Thesis, IPEN-Instituto de 
Pesquisas Energéticas e Nucleares, São Paulo.

[8] Woodruf, W.L. (1983) COBRA-3C/RERTR-A Thermal-Hydraulic Sub-Channel Code with Low Pressure Capabilities and Supplement. Argone National Laboratory.

[9] Obenchain, C.F. (1969) Paret-A Program for the Analysis of Reactor Transients, IDO 17282. Idaho National Engineering Laboratory.

[10] Barry, R.F. (1963) LEOPARD: A Spectrum Dependent Non-Spatial Depletion Code, WCAP-3269-26. Westinghouse Electric Corporation.

[11] Kerr, W., King, J.S., Martin, J.C. and Wehe, D.K. (1991) The Nuclear Ford Reactor Demonstration Project Goes the Evaluation and Analysis of Low Enrichment Fuel. Final Report, Argonne National Laboratory, Argonne.

[12] Barhen, J., Rhotenstein, W. and Taviv, E. (1978) The Hammer Code System Technion. NP-565, Israel Institute of Technology, Haifa.

[13] Little, W. and Hardie, R. (1969) 2DB User's Manual. Revision I, BNWL-831-Rev-1, Battelle Pacific Northwest Laboratory, Richland.

[14] Fowler, T.B., Vondy, D.R. and Cunningham, G.W. (1972) Nuclear Reactor Core Analysis Code: Citation. Oak Ridge National Laboratory ORNL-TM-2496.

[15] Castro, A. and Almeida, J. (1996) Experimento de Perda de Carga nos Elementos Combustíveis e de Controle do IEA-R1. IPEN-CNEN/SP Relatório Interno PSI.RAT.IPEN-R00, RELT.001.R00, São Paulo.

[16] Castro, A., Almeida, J. and Umbehaun, P. (1997) Experimento de Perda de Carga nos Elementos de Irradiação de Amostras Refrigerados a Água e Irradiador de Silício. IPEN-CNEN/SP (Relatório Interno PSI.ROI.IEA-R1.026, RELT.002.R00), São Paulo.

[17] Umbehaun, P.E. and Torres, W.M. (2003) Thermal-Hidraulic Analysis of the IEA-R1 Research Reactor-A Comparison between Ideal and Actual Conditions. Proceedings of 17 th International Congress of Mechanical Engineering, COBEM, Brazil.

[18] Torres, W.M., Umbehaun, P.E., Andrade, D.A. and Souza, J.A.B. (2003) A MTR Fuel Element Flow Distribution Measurement-Preliminary Results. Proceedings International Meeting on Reduced Enrichment for Research and Test Reactors, RERTR, Chicago, 5-10 October 2003.

[19] Torres, W.M., Umbehaun, P.E., Baptista Fo, B.D., Almeida, J.C. and Souza, J.A.B. (2001) Distribuição de vazão no núcleo do reator de pesquisas IEA-R1. Proceedings of the 16th Brazilian Congress of Mechanical Engineering, COBEM, Uberlândia, 26-30 November 2001.

[20] Torres, W.M., Umbehaun, P.E., Baptista Fo, B.D., Silva, J.E.R., Zeituni, C. and Silva, A.T. (2002) Desenvolvimento e utilização de elementos instrumentados e sistemas de inspeção visual para reatores nucleares de pesquisa. Proceedings of the 2 th National Congress of Mechanical Engineering, CONEM, João Pessoa, Brazil, 12-16 August 2002.

[21] Chavez, J., Barrera, M., Jimenez, O., Lisboa, J. and Marin, J. (2000) LEU Fuel Fabrication Program for the RECH-1 Reactor. Las Vegas.

[22] Schreiner, P. and Krull, W. (1999) The New Compact Core Design of the FRG-1.

[23] Nuclear Safety Analysis Division (2001) RELAP5/MOD3.3 Code Manual Vol.1: Code Structure, System Models, and Solution Methods. Nuclear Safety Analysis Division Office of Nuclear Regulatory Research U.S. Nuclear Regulatory Commission, Information Systems Laboratories, Inc., Rockville.

[24] Nuclear Safety Analysis Division (2001) Models and Correlations. Nuclear Safety 
Analysis Division, Office of Nuclear Regulatory Research U.S. Nuclear Regulatory Commission, Information Systems Laboratories, Inc., Rockville.

[25] Lavialle, G. (2011) SSTH/LDAS/EM/2005-035. Noel, B., DEN Platform for Thermal Hydraulic Simulation of Reactors with Focus on System CATHARE Code. 